\title{
Deficits in recognition of random shapes with changed visual fields
}

\author{
D. S. LORDAHL', K. M. KLEINMAN, BARBARA LEVY, N. A. MASSOTH, M. S. PESSIN, MARTHA STORANDT, \\ RUTH TUCKER AND J. M. VANDERPLAS \\ WASHINGTON UNIVERSITY
}

\begin{abstract}
Abstraet
Four random shapes were presented twice to each of 96 Ss under monocular viewing. Two shapes were presented to the left visual field and two to the right. In the test series, including control shapes, Ss experienced significant difficulty in recognizing those shapes which had been changed from one visual field to the other.
\end{abstract}

\section{Problem}

Numerous reports indicate that visual information projected to one cerebral hemisphere is transmitted to the other hemisphere primarily by the corpus callosum (Sperry, 1964; Myers, 1956; and Trevarthen, 1962). Deficits in humans with complete sectioning of the corpus callosum (Akelaitis, 1941) have not been pronounced for certain types of recognition tasks, usually involving familiar stimuli. Myers (1956) has suggested that this lack of observed deficits in humans may be the result of previous experience with materials or the task.

The present experiment tests for a deficit in recognition of visual stimuli when such recognition requires the transfer of information between the two cerebral hemispheres. The use of random shapes as stimuli is intended to reduce past experience and symbolic representation by Ss.

\section{Method}

St imuli. Eight 24-point random shapes of low association value (Vanderplas \& Garvin, 1959) were photographed so as to appear as solid black figures on a white background (Fig. 1).

Apparatus. A Gerbrands' tachistoscope was used to present the shapes for Ss' viewing. Stimuli were presented so that their approximate centers of gravity were $8^{\circ}$ of visual angle to the direct left or right of the fixation point. The maximum visual angle subtended by the shapes was about $4^{\circ}$. Two lever action switches were mounted vertically side by side on the table top for response by the $\mathrm{S}$.

Procedure. The Ss were 96 volunteers from undergraduate psychology courses. Monocular viewing conditions were used throughout the experiment, which was divided into two portions, Exposure and Test sessions. Ss were first given the Exposure session, in which each of the four exposure shapes (lettered A, B, C, and D, Fig. 1) were presented twice. Two of these shapes were shown in left visual field both times they occurred, while the other two were always shown in the right visual field.

The Test session was begun between 1 and 2 min. following the conclusion of the Exposure trials and

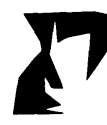

A



W

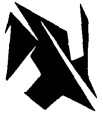

B

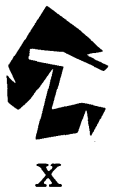

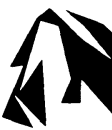

C

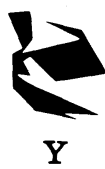

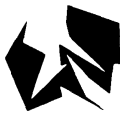

D

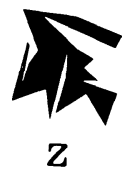

Fig. 1. Twenty-four point shapes used as exposure stimuli $(A, B, C$, and $D)$ and as control stimuli ( $W, X, Y$, and $Z$ ).

consisted of the presentation of eight shapes, the four exposure and four control shapes (Lettered $\mathrm{W}, \mathrm{X}$, $Y$, and Z, Fig. 1). On these trials, Ss were required to indicate each time (by pulling the appropriate lever) whether or not they recognized the shape as having been presented during the Exposure session.

In the Test series, all shapes were presented to a single visual field, either the left or right depending upon S's assigned treatment. All exposure durations were $.3 \mathrm{sec}$.

The three major independent variables of Exposure Eye, Test Eye, and Test Field were studied with a factorial design. This gave eight treatments. Within each of these treatments, all six of the possible combinations of the four exposure shapes (with regard to left or right visual field) were used in the Exposure sessions. These conditions required $48 \mathrm{Ss}$ for a complete replication of the design. The order of stimulus presentation during the Exposure and test sessions was arranged randomly for each $\mathrm{S}$.

The first replication was conducted by six Es working in three set pairs. Each pair of Es ran $16 \mathrm{Ss}$, with randomly assigned conditions. The second replication was conducted by a single $\mathrm{E}$, different from those mentioned above.

Ss were carefully instructed as to the importance of maintaining strict fixation on each trial and a "ready" signal was given about $2 \mathrm{sec}$. before each trial in order to aid in attaining this goal. Instructions included the information that the $\mathrm{S}$ would be asked later to recognize the shapes seen in the Exposure trials. 


\section{Results}

The data of major interest are the numbers of recognition responses to the exposure shapes. These totals may be divided into two classes for each of the eight experimental treatments, as shown in Table 1. Stimuli shown in the same visual field in both Exposure and Test sessions will be designated as $F_{O}$ stimuli and those which were shown in the field opposite to the Test field will be called $F_{X}$ stimuli. Note that each $S$ was given two stimuli of each kind.

The data in Table 1, including the replication classification, were subjected to an analysis of variance. The interaction of Exposure Field and Test Field (corresponding to the $F_{O}-F_{X}$ variable) was highly significant $(\mathrm{F}=16.51, \mathrm{df}=1 / 80, \mathrm{p}<.001)$. This term is based on the result of 130 correct recognitions of stimuli presented to the same visual field (hemisphere) versus 96 recognitions for stimuli presented to a different visual field.

The triple interaction of Exposure Field by Exposure Eye by Test Eye was also significant in this analysis $(\mathrm{F}=18.51, \mathrm{df}=1 / 80, \mathrm{p}<.001)$ however this term interacted in turn with the replications $(F=5.71, p<.025)$. The final source of significant variation was the interaction of Exposure Eye by Exposure Field by Replication $(\mathrm{F}=991, \mathrm{df}=1 / 80, \mathrm{p}<.025)$.

The tendency for $F_{O}$ stimuli to be recognized to a greater degree than $F_{\mathbf{X}}$ stimuli was also tested by comparing the number of Ss showing this preference $(\mathrm{N}=40)$ to the number showing the opposite tendency $(\mathrm{N}=17)$ with chi square test. This resulted in a chi square (corrected for continuity) of 8.48 , which is significant beyond the .01 level.

Positive responses were made to $67.7 \%$ of $\mathrm{F}_{\mathrm{O}}$ stimuli, $50.0 \%$ of $\mathrm{F}_{\mathrm{X}}$ stimuli and $33.6 \%$ of the control stimuli. In order to assess whether or not transfer took place on the $\mathbf{F}_{\mathbf{X}}$ stimuli, each $\mathbf{S}$ was assigned an expected chance score for $F_{X}$ stimuli based on his number of positive responses to the control shapes. The number of Ss exceeding their expected score was 51, the number falling below their expected score was 28 . Comparison of these totals yielded a chi square of 6.13 which, with $1 \mathrm{df}$, gave a $\mathrm{p}<.02$.
TABLE I

Total Correct Responses to Exposure Stimuli for Constant $\left(F_{0}\right)$ and Changed $\left(F_{X}\right)$ Fields

\begin{tabular}{l|rrrr|} 
Exposure-Test & \multicolumn{5}{c}{ Exposure-Test Eye Order } \\
Field Order & L-L & L-R & R-R & R-L \\
L-L $\left(F_{0}\right)$ & 17 & 12 & 19 & 14 \\
R-L $\left(F_{x}\right)$ & 9 & 18 & 8 & 12 \\
R-R $\left(F_{0}\right)$ & 16 & 20 & 14 & 18 \\
L-R $\left(F_{x}\right)$ & 14 & 10 & 13 & 12 \\
\hline
\end{tabular}

${ }^{\star} L$ indicates left and $R$ indicates right

\section{Diseussion}

These results certainly support the hypothesis that tranmission of visual information from one brain hemisphere to the other is more difficult than utilization of visual information restricted to a single hemisphere. However, the present study is not designed to rule out all alternative explanations. For example, it is also possible that the short exposure durations have restricted perception of the shapes to only those portions closest to the fixation point. In the present study, these portions of a figure would be most removed from the fixation point under the $F_{x}$ test conditions. Such considerations allow only a tentative inference about inter-hemispheric transfer from the present data.

The significance of the higher order interactions in the analysis of variance of correct recognition scores has defied reasonable explanation by the authors.

\section{Referenees}

Akelaitis, A. J. Studies of the corpus callosum II. The higher visual functions in each homonymous field following complete section of the corpus callosum. Arch. Neurol. Psychiat., 1941, 45, 788-796.

Myers, R. E. Function of the corpus callosum in interocular transfer. Brain, 1956, 79, 358-363.

Sperry, R. W. The great cerebral commissure. Scient. Amer., 1964, $210,42-52$.

Trevarthen, C. B. Double visual learning in split-brain monkeys. Science, 1962, 136, 258-259.

Vanderplas, J. M., \& Garvin, E. A. Complexity, association value, and practice as factors in shape recognition following pairedassociates training. J. exp. Psychol., 1959, 57, 155-163.

Note

1. Now at the University of Miami, Coral Gables, Florida. 